\title{
Modeling Urban Sewers with Artificial Fractal Geometries
}

\author{
Scott Martin Jeffers and Franco Montalto
}

Drexel University, Philadelphia, Pennsylvania.

\begin{abstract}
Sewer models are used to simulate complex urban hydrology. However, the development of empirical models can be difficult given the limited availability of sewer plans and the time required to incorporate the system layout. In contrast, fractal geometries can be used to overcome some of these constraints. In this study, two highly impervious residential urban catchments (54 ha and 24 ha) serviced by a combined sewer in East Boston, Massachusetts are modeled using the Storm Water Management Model (SWMM). Two different modeling techniques are compared. The first is an empirical model using the physical characteristics of the network obtained from municipal sewer maps; the second is an abstract conceptual model incorporating fractal scaling laws often used to describe natural river basins. Both modeling approaches were calibrated with 1 month of empirical 5 min interval sewer flow measurements. The models predicted similar total discharge volumes and peak flows over the course of 10 observed rainfall events $(0.5 \mathrm{~mm}$ to $12.7 \mathrm{~mm}$ ). Model resolution was tested by simulating the 54 ha catchment as 1, 10, 24 and 173 subcatchments; accurate simulations could be produced for all of the resolutions.
\end{abstract}

\section{Introduction}

Stormwater runoff is a major concern for cities because of its detrimental effects on ecosystems, water quality, and sewer infrastructure. Descriptions of the hydrologic and hydraulic $(\mathrm{H} \& \mathrm{H})$ flow processes of urban drainage systems can be provided by computer models and simulations. One of the most widely used methods for $\mathrm{H} \& \mathrm{H}$ modeling is the United States Environmental Protection Agency's (USEPA) Storm Water Management Model (SWMM), a dynamic rainfall-runoff-subsurface runoff simulation model that can be used for both single event and long term simulations of surface and subsurface hydrology for urban and suburban environments (USEPA 2017). SWMM is a robust modeling method that can account for a wide range of hydrologic processes including time-varying rainfall, evaporation of standing surface water, snow accumulation and melting, rainfall interception and depression storage, infiltration of rainfall into unsaturated soil layers, percolation of infiltrated water into groundwater layers, interflow between groundwater and the drainage system, nonlinear reservoir routing and overland flow, and the capture and retention of rainfall and runoff with various types of low impact development (LID) practices (USEPA 2017).

The development of accurate and reliable model of existing sewers can be challenging due to the (un)availability of sewer infrastructure plans, the amount of time required to create a detailed $\mathrm{H} \& \mathrm{H}$ model, and the limited availability of sewer flow data with which to calibrate a model. The use of conceptual sewer models can help to circumvent these issues if the models produce reasonable results that are comparable to those of typical models of existing sewers in both calibrated and uncalibration scenarios. Conceptual, or artificial, abstract networks can be designed based

on fractal geometries (namely Strahler order and bifurcation) and have been extensively analyzed in natural river basins (Jeffers 2017; Cantone and Schmidt 2011).

Natural river basins generally take a dendritic shape. A typical binary dendritic fractal geometry will have one trunk branching out into two half sized branches repeatedly for a number of generations. Tokunaga modified this binary tree to include more branches so as to increase the drainage density and be more representative of natural geometries; an example is shown in Figure 1 (Turcotte and Newman 1996). The drainage density of the network can be defined by the fractal dimension (D) where $D=1$ represents a single dimension line (and no drainage area) and $\mathrm{D}=2$ represents a completely filled 2-dimensional square (with maximum drainage density) as shown in Figure 2.

a)

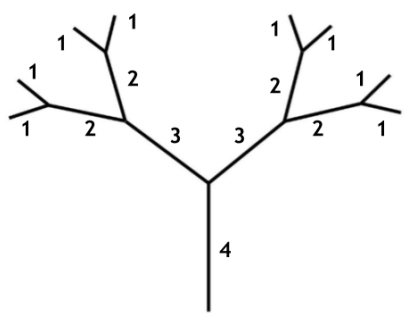

Figure 1 (a) Binary fractal tree showing four Strahler stream orders; (b) the Tokunaga fractal method includes space filling branches more characteristic of the drainage density found in natural stream networks: the additional branching segments are labelled by their Strahler order (adapted from Turcotte and Newman 1996).

Jeffers, Scott Martin and Franco Montalto. Modeling Urban Sewers with Artificial Fractal Geometries.

Journal of Water Management Modeling 26: C455. doi: 10.14796/JWMM.C455.

(c) CHI 2018. www.chijournal.org ISSN 2292-6062. 


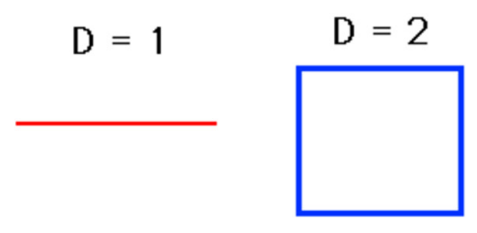

Figure 2 Dimensions are typically thought of as length (1st dimension), width (2nd), and depth (3rd); Ryan (2007).

Fractals can be represented mathematically by power law expressions because they display scale invariance between geometric scales. Scale invariance means that the pattern observed at a given scale will be identical to the pattern at both larger and smaller scales. In 1957, John Hack of the United States Geological Survey empirically determined the scale invariant power law relationships that relate river basin length to the contributing drainage area, now known as Hack's Law (1957). In 1967, French mathematician Benoit Mandelbrot began implementing and refining power law geometry in natural systems with fractals. Typically, river basin geometry is defined using Strahler stream ordering, a classification scheme whereby each tributary is numerically ranked such that a first-order stream has no tributaries, a second-order stream is the confluence of two first-order streams, and so on. By combining Strahler ordering with fractal power laws, Rodriguez-Iturbe and Rinaldo (2001), in Fractal River Basins: Chance and Self-Organization, introduce methods to analyze natural river basin geometries and the effect they have on drainage networks. Because the natural world rarely shows such perfect invariance, fractal models are best employed with stochastic variance. That is to say that the probabilistic rules governing a system will be the same at each scale, but the way the pattern is manifest will have random elements determined by those rules (Veneziano and Langousis 2010).

These methods have previously been applied to generate conceptual sewer networks. The artificial network generator (ANGel) developed by Ghosh et al. (2006) allows for the stochastic creation of a sewer network using Tokunaga fractal geometry. The program creates pipes and nodes at various spatial scales. Ghosh et al. used this method to investigate scale effects in hydrologic models by comparing the predicted runoff of a large $\left(4.66 \mathrm{~km}^{2}\right)$ catchment in the lower Charles River in Boston that was divided into 4, 18 and 401 subcatchments with increasing drainage densities (total pipe length). The results showed little difference in predicted total runoff volume when simulated at the different resolutions, but the predicted peak runoff rates were significantly different at lower resolutions. Comparison of the model results showed that was also a dual effect on peak flow rates: larger storms in low resolution models tended toward less flow while smaller storms resulted in more flow. Ghosh and Hellweger surmised that the effect came from the differences in both the length of overland flow and conduit routing (Ghosh and Hellweger 2012). In this study there are no observed results, only modeled predictions.
Möderl et al. (2009) developed another method of generating conceptual networks, the case study generator (CSG). This method stochastically generates nodes and conduits based on Galton-Watson branching, another type of dendritic geometry typically associated with a family trees. This tool was used to simulate 10000 different artificial networks to analyze flooding and combined sewer overflows alongside two actual networks in Austria. Unlike the ANGel model, this method is able to simulate many different networks at one time whereas ANGel only generates one. However, Galton-Watson geometry is less similar to urban networks than Tokunaga geometry (with all branching occurring in generally one direction) and because currently CSG is not georeferenced, it is less practical for GIS applications that analyze real networks.

Ghosh and Hellweger (2012) and Möderl et al. (2009) demonstrated the use of fractal scaling rules to develop artificial sewer networks for urban $\mathrm{H} \& \mathrm{H}$ modeling, but did not meaningfully characterize their precision by comparison with observations. While the ANGel model was able to simulate comparable results for one observed storm (Ghosh and Hellweger reported no numerical analysis of accuracy), a more comprehensive evaluation of the approach would ideally consider multiple storms and multiple sewer networks with thorough evaluation of the goodness of fit of predictions to observations. Likewise, Möderl et al. (2009) only compared two storms to their model without any detailed analysis of the differences in hydrologic response between the two, reporting only the surface ponding results as the criteria for performance. Further, from a modeling perspective, understanding the sensitivity of the critical modeling parameters in a conceptual network is important for future implementation and application to other unique networks.

One of the main motivations for developing conceptual sewer networks is to simplify the urban $\mathrm{H} \& \mathrm{H}$ modeling process. Several researchers have already shown that models that simplify urban drainage networks can produce reasonable results. This literature focuses on subcatchment aggregation and conduit skeletonizing. For example, Huber et al. (2006) showed that for a 7 ha urban catchment, an empirical model that accounted for $\mathrm{H} \& \mathrm{H}$ processes on every parcel performed as well as a lower resolution model utilizing street blocks as the basic hydrologic response unit (HRU), having 118 versus 14 subcatchments. A similar result was obtained by Goldstein (2011) who showed that a block scale SWMM model performed as well as, if not better than, a high resolution empirical model when the latter incorporated all the pipes and features of an urban block. For larger modeled areas, low resolution can create error. This was shown by Cantone and Schmidt (2009) who created an empirical model of a 5.2 ha catchment using subcatchment resolutions ranging from 44 to 1 and found that the most accurate predictions were obtained with 8 subcatchments. Modeling the entire catchment as one subcatchment resulted in a greater time of concentration and lower peak flows and the greatest error. This finding was replicated in a 341 ha catchment modeled with between 773 and $1 \mathrm{HRUs}$, which showed that the most accurate model had 65 subcatchments. The authors noted that this result is troublesome because it is common for municipalities (in their case 
the City of Chicago) to utilize low resolution models for the reasons cited in the introduction of this paper.

The focus of this study is to test the accuracy of artificial sewer models built using fractal scaling laws for urban watersheds. We will accomplish this goal by using Tokunaga fractal geometries found in natural river basins to represent urban catchments through the ANGel program. The hydrologic response of the fractal networks will be analyzed for multiple storms and observed catchment discharge for two sewersheds. We will conduct sensitivity analysis to inform the model calibration. Evidence supporting the application of fractal geometries to urban catchments can be found in the related dissertation (Jeffers 2017).

\section{Methodology}

\subsection{Site Description}

East Boston is a neighbourhood in Boston, Massachusetts serviced by both separate and combined sewers. The study area in this analysis included two sections of the combined sewer network. The first section of the sewer network services a 54 ha highly impervious (land use shown in Figure 3) combined sewer in a mostly urban residential area (201 people/ha) which will be referred to as East Boston section 77 (US Census Bureau 2010). According to soil survey data from the Natural Resource Conservation Service, the typical soil profile is silty loam with a deep infiltration rate of $0.71 \mathrm{~cm} / \mathrm{h}$ and topographic slopes ranging from $3 \%$ to $15 \%$ (NCRS 2017). The second section is 22 ha, referred to as East Boston section 81. It is adjacent and similar to section 77 in that it is a highly impervious residential catchment serviced by a combined sewer. Due to its proximity to section 71 , its soil survey was the same as section 77. Both section 77 and section 81 were chosen because they drain to a single point at a regulator where observed sewer data were available.

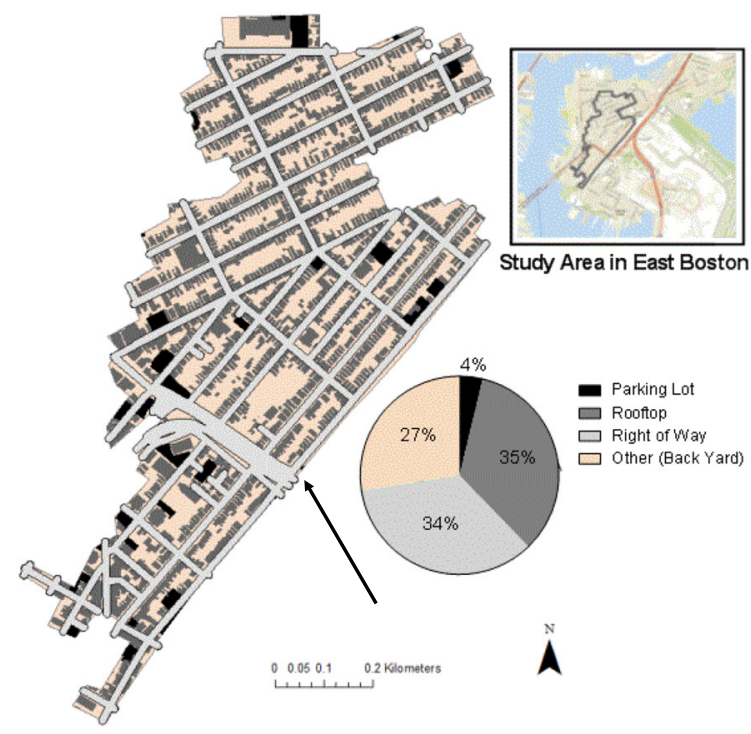

Figure 3 Land use of East Boston section 77; the location of the regulator is identified by the arrow.

\subsection{Model Development}

An empirical model of the area was developed with PCSWMM 2017 (with SWMM engine version 5.1.011; USEPA 2017; CHI 2017) using GIS data provided by the Boston Water Sewer Commission. The model included pipe sizes, inverts, riser covers and catchbasin locations, topography, and all special sewer points including regulators based on the map details. One month of $5 \mathrm{~min}$ interval sewer flow data from 2016-04-15 to 2016-05-15 was obtained from the downstream regulator for use in calibrating and validating the model. Subcatchments were modeled at the block scale. The model was run over the course of the observed sewer flow period using rainfall data collected at 15 min intervals from a tipping bucket rain gauge located in Charlestown $\sim 1.5 \mathrm{~km}$ away from the catchment. This period included 10 rain events ranging from $0.51 \mathrm{~mm}$ to $12.7 \mathrm{~mm}$ in total rainfall. The results from the simulated network were calibrated to the observed flow by adjusting the most sensitive parameters, discussed later in this section. SWMM simulations were run under dynamic wave routing, Horton infiltration (maximum rate $76.2 \mathrm{~mm} / \mathrm{h}$, minimum rate $12.7 \mathrm{~mm} / \mathrm{h}$ ), $5 \mathrm{~min}$ time steps routed at $5 \mathrm{sec}$, damped inertial terms, both normal flow criteria, and the Hazen-Williams equation for the force mains. Evaporation rates of $5.3 \mathrm{~mm} / \mathrm{d}$ in April and $6.1 \mathrm{~mm} / \mathrm{d}$ in May were obtaining from the nearby Logan International Airport using the National Stormwater Calculator (USEPA 2018). Seasonal effects were not explored because of the limited availability of observed flow data.

A second artificial model was developed based on fractal scaling laws using the ANGel program. ANGel version 1.0 was provided by Dr. Ferdi Hellweger of Northeastern University. In the user interface of the ArcGIS plugin ANGel, a shapefile is first imported into ArcGIS, in this case the outline of the East Boston drainage area. Using ANGel, the start and end points of the network are defined. Next, the number of generations is defined as being equivalent to the maximum Strahler stream order in the system. ANGel employs the Tokunaga fractal tree such that it begins with a main trunk and then branches out at $90^{\circ}, 180^{\circ}$ and $270^{\circ}$. The pattern is repeated at each branch based on the selected stream order. ANGel also allows for irregularity in the fractal so there are stochastically generated irregular (non- $90^{\circ}$ ) bends in the Tokunaga branching that deviate from perfect geometry. This option was enabled in the network generation with the default value of 30 . Additionally, the shape of the network can be restricted by the catchment boundary shapefile such that all pipes are contained in the catchment. Based on the artificial HRUs generated this way, access risers, pipes, and subcatchments are exported to a GIS-enabled SWMM model using the built-in ArcGIS export tool (Ghosh et al. 2006). Inverts in the artificial network were assumed to be based on a $2 \%$ pipe slope with the outfall of the network as the lowest point. Pipe diameters were selected to eliminate all flooding and surcharge by the sewer network to avoid additional complexity that might arise from undersizing the network; no observed storm was large enough to cause a 
surcharge in the empirical model. The resulting networks from the two models are shown in Figure 4.
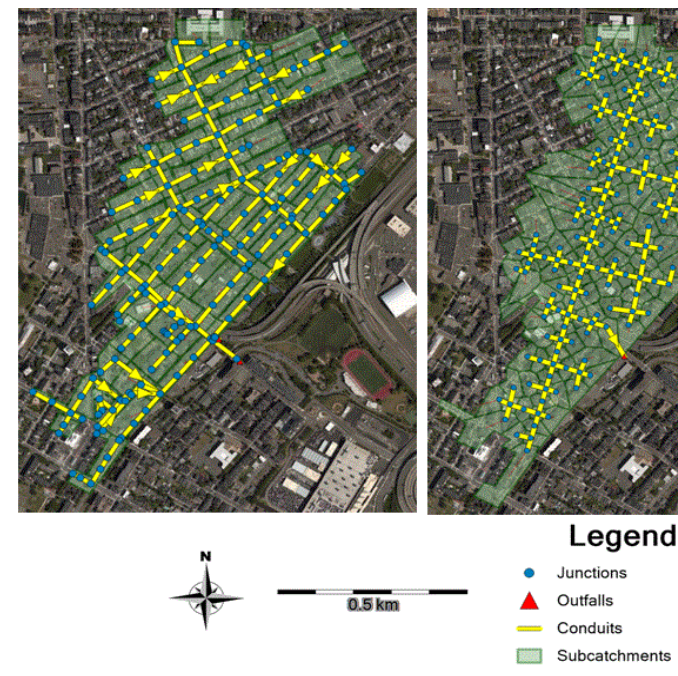

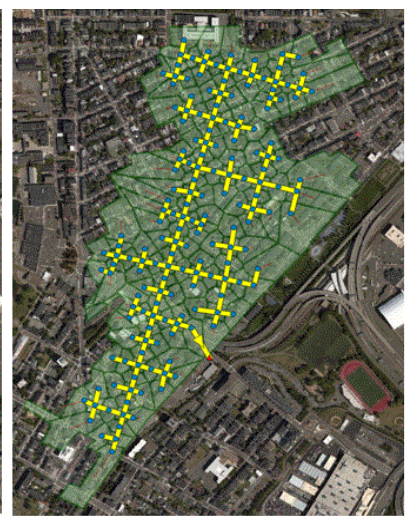

egend
Figure 4 Images from PCSWMM showing the empirical (left) and the fractal (right) networks for section 77; the regulator in this submodel is the lowest point.

The study area of East Boston is serviced by a sewer which combines sanitary and stormwater flows in one pipe. As a result, there is dry weather flow (DWF) in the system at all times. DWF was estimated from a week of observed DWF using the sewer flow monitoring data. In SWMM, DWF can be represented as a weekly time pattern multiplied by an average flow and used at nodes within the simulation. DWF was added to both the actual network and the fractal model at each outfall. The time pattern was calculated using PCSWMM and the average DWF was determined over the observed period as shown in Figure 5. The average DWF was $0.053 \mathrm{~m}^{3} / \mathrm{s}$ and the modeled DWF had an NSE of 0.73 over the observed period.

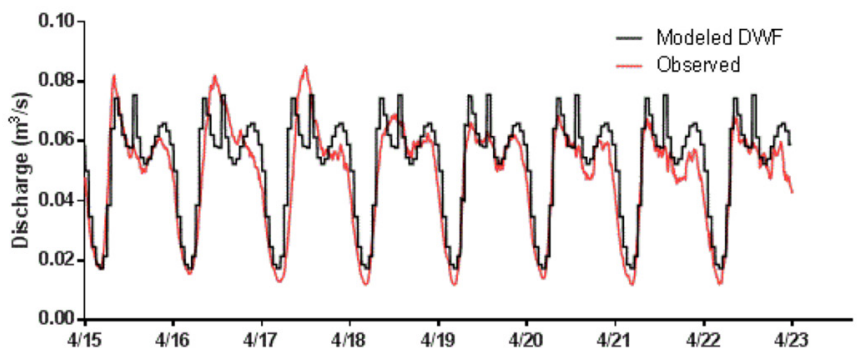

Figure 5 DWF analysis from 2016-04-15 to 2016-04-23; average DWF was $0.053 \mathrm{~m}^{3} / \mathrm{s}$ and NSE of the modeled DWF over the observed period was 0.73 .

Calibration of the models was accomplished by varying subcatchment slope, percent imperviousness, storage, length, conduit roughness, and baseline DWF using the PCSWMM SRTC calibration tool to adjust each parameter on a sliding scale to optimize peak flows and using the total discharge of four select events (CHI 2018). The remaining six storms were used to validate

the model. Sensitivity analysis was performed, incrementing each parameter by $25 \%$ of its original value, to examine the effect on total discharge and peak discharge rate for the 2016-05-04 12.45 mm event.

Several methods were used to assess model accuracy. Moriasi et al. (2007) provide an extensive literature review of watershed simulations which compares simulations to observed results and recommend statistical measures for evaluation, including the Nash-Sutcliffe efficiency coefficient (NSE), in addition to graphical analysis. In a technical code of practice for hydraulic modeling of sewer systems, the Wastewater Planning Users Group (2002) also developed criteria to assess model quality. They recommend that when using a minimum of three observed storms the peak flow rates should be in the range $-15 \%$ to $+25 \%$ while the total volume should be in the range $-10 \%$ to $+20 \%$. The percentage errors between the predicted and observed total and peak discharge is given in Figure 5.

\subsection{Uncalibrated Model Development}

A second comparison of an empirical model to a theoretical model was made for an adjacent catchment, section 81, and compared to observed results at the regulator. The two models are shown in Figure 6. The purpose of this exercise was to determine the replicability of the findings without direct calibration. Subcatchment percent impervious was determined to be $83 \%$ based on land area characteristics, as shown in Figure 7. Manning's $n$ for overland flow was assumed to be 0.04 based on dense residential conditions in medium rainfall (Tory R. Walker Engineering 2016). Pipe roughness $n$ was assumed to be 0.015 based on USEPA recommendation for sewers with inlets and risers under normal conditions (Rossman 2017). Subcatchment flow length is a function of area divided by width. Pipe slope was assumed to be $2 \%$ in the fractal network as is typical in the area. The model was simulated over the same 10 events as section 77 and compared to observed sewer flow at the outfall. A summary of the total pipe lengths, number of junctions and subcatchments in each model is summarized in Table 1.
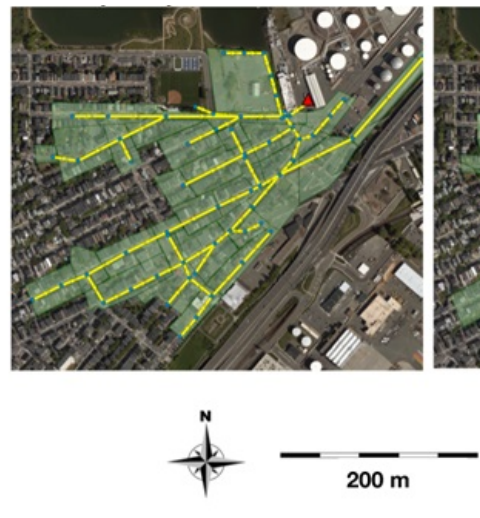

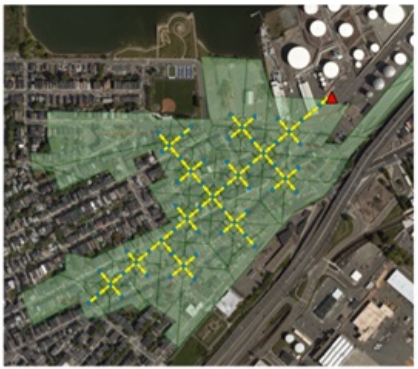

Legend

- Junctions

$\Delta$ Outfalls

$=$ Conduits

Subcatchments

Figure 6 Images from PCSWMM comparing the empirical (left) and fractal (right) networks for section 81; the regulator in this submodel is the lowest point, at the outfall. 


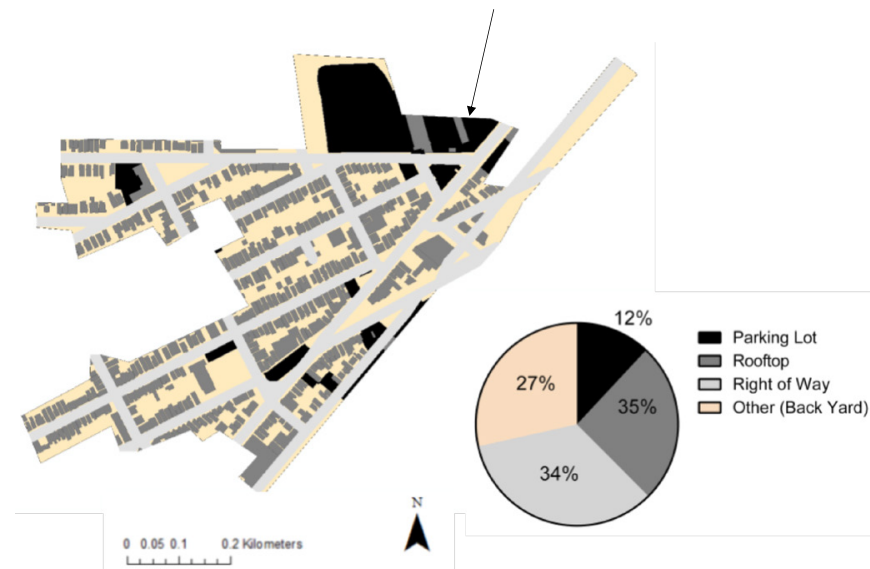

Figure 7 Land use of section 81; the location of the regulator is identified by the arrow.

Table 1 Summary of the network geometries in the empirical and fractal models.

\begin{tabular}{|c|c|c|c|c|c|}
\hline \multicolumn{6}{|c|}{ Network Summary } \\
\hline & $\begin{array}{l}\text { Total Pipe } \\
\text { Length (m) }\end{array}$ & Junctions & Subcatchments & Total Area (ha) & $\begin{array}{c}\text { Longest Flow } \\
\text { Path }(\mathrm{m})\end{array}$ \\
\hline \multicolumn{6}{|l|}{ Section 77} \\
\hline Empirical & 10502 & 183 & 128 & 54 & 1377 \\
\hline Fractal & 6889 & 173 & 173 & 54 & 1234 \\
\hline \multicolumn{6}{|l|}{ Section 81} \\
\hline Empirical & 4394 & 65 & 35 & 22 & 818 \\
\hline Fractal & 2195 & 60 & 59 & 22 & 695 \\
\hline
\end{tabular}

\section{Results}

The results of the sensitivity analysis are shown in Figure 8 for both the empirical and fractal models. The only sensitive parameters for total catchment discharge were the percent imperviousness and baseline DWF, and both models were equally sensitive. Baseline DWF and percent impervious were also highly sensitive parameters in both models for predicting peak discharge. A key difference between the two models was that the empirical model was more sensitive to surface and conduit roughness than the fractal model. The final selected calibrated parameters used in the simulations are shown in Table 2.
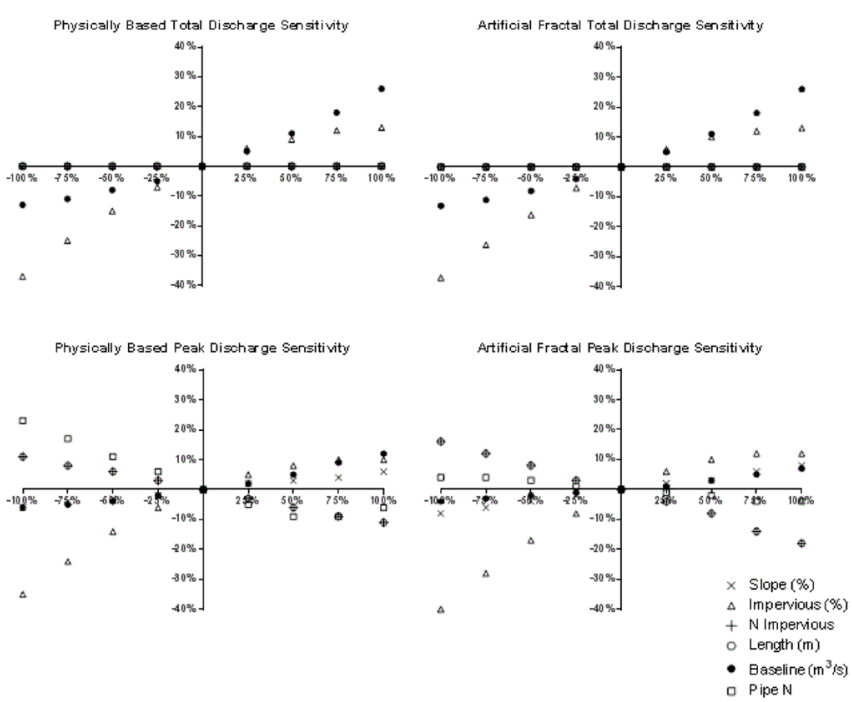

Figure 8 Sensitivity analysis of the empirical and fractal simulated network in East Boston section 77 for the 2016-05-04 $12.45 \mathrm{~mm}$ event; percentages on the $x$-axes represent changes of $25 \%$ of its base value and on the $y$ axes the resulting effects.

Table 2 Calibrated sensitive parameters in each model for section 77.

\begin{tabular}{lcccccc}
\hline \multicolumn{7}{c}{ Calibrated Parameters } \\
& Slope (\%) & \% Impervious & $n$ Impervious & $\begin{array}{c}\text { Catchment } \\
\text { Length }\end{array}$ & Pipe $n$ & DWF \\
\hline Fractal & 3.7 & 70.9 & 0.047 & $251 \mathrm{~m}$ & 0.005 & $0.053 \mathrm{~m}^{3} / \mathrm{s}$ \\
Empirical & 3 & 69.5 & 0.039 & $244 \mathrm{~m}$ & 0.003 & $0.053 \mathrm{~m}^{3} / \mathrm{s}$ \\
\hline
\end{tabular}

Descriptions of the 10 simulated rainfall events in section 77 , which ranged from $0.51 \mathrm{~mm}$ to $12.7 \mathrm{~mm}$ total precipitation, are summarized in Table 3. This table shows the date, rainfall depth and duration of each of the storms in addition to the total discharge, peak flow rate and the time to peak (lag time) for both models. The percentage error and NSE are listed for both models relative to the observed flow. Figure 9 provides a similar event summary, graphically comparing the simulated to observed total discharge and peak flow for both models. The results are plotted within the bounds of the Wastewater Planning Users Group criteria for good model performance. Select hydrographs are shown in Figure 10 for 2016-04-26 (6.68 mm), 2016-05-01 (12.5 mm), 2016-05-03 (2.54 mm) and 2016-05-04 (12.45 mm). The observed and simulated flows in both models are shown along the rainfall time series. 
Table 3 Results of the 2016-04 to 2016-05 simulation for section 77; events used in the calibration process are denoted by ${ }^{*}$.

\begin{tabular}{|c|c|c|c|c|c|c|c|c|c|c|c|}
\hline \multirow[t]{4}{*}{ Rain Events } & Event & $1^{*}$ & $2^{*}$ & $3^{*}$ & 4 & 5 & $6^{*}$ & 7 & 8 & 9 & 10 \\
\hline & Date & 19-Apr & 23-Apr & 26-Apr & 1-May & 3-May & 4-May & 5-May & 6-May & 8-May & 13-May \\
\hline & Rainfall (mm) & 0.51 & 2.29 & 6.86 & 12.7 & 2.54 & 12.45 & 3.81 & 2.29 & 0.51 & 2.54 \\
\hline & Duration (h) & 6 & 17 & 8 & 27 & 13 & 11 & 13 & 9 & 6 & 10 \\
\hline \multirow[t]{3}{*}{ Observed } & Total Discharge $\left(\mathrm{m}^{3}\right)$ & 1111 & 3412 & 4010 & 9002 & 3398 & 7139 & 3579 & 2047 & 1943 & 2095 \\
\hline & Peak (m³/s) & 0.07 & 0.1 & 0.58 & 0.69 & 0.12 & 0.5 & 0.11 & 0.13 & 0.11 & 0.12 \\
\hline & Time to Peak (min) & 180 & 65 & 25 & 15 & 20 & 35 & 10 & 10 & 105 & 10 \\
\hline \multirow[t]{6}{*}{ Empirical Model } & Total Discharge $\left(\mathrm{m}^{3}\right)$ & 1191 & 3693 & 4185 & 9939 & 3806 & 6615 & 2911 & 2083 & 1449 & 2965 \\
\hline & $\%$ Error & $7 \%$ & $8 \%$ & $4 \%$ & $9 \%$ & $11 \%$ & $-8 \%$ & $-23 \%$ & $2 \%$ & $-34 \%$ & $29 \%$ \\
\hline & Peak (m³/s) & 0.08 & 0.09 & 0.59 & 0.84 & 0.14 & 0.47 & 0.1 & 0.16 & 0.1 & 0.16 \\
\hline & $\%$ Error & $12 \%$ & $-11 \%$ & $2 \%$ & $18 \%$ & $12 \%$ & $-6 \%$ & $-14 \%$ & $21 \%$ & $-15 \%$ & $22 \%$ \\
\hline & NSE & 0.85 & 0.60 & 0.93 & 0.88 & 0.72 & 0.92 & 0.53 & 0.33 & -0.96 & -0.05 \\
\hline & Time to Peak (min) & 180 & 40 & 20 & 15 & 35 & 25 & 25 & 25 & 60 & 35 \\
\hline \multirow[t]{6}{*}{ Fractal Model } & Total Discharge $\left(\mathrm{m}^{3}\right)$ & 1192 & 3497 & 4318 & 10203 & 3868 & 6872 & 2945 & 2113 & 1454 & 3033 \\
\hline & \% Error & $7 \%$ & $2 \%$ & $7 \%$ & $19 \%$ & $12 \%$ & $-4 \%$ & $-22 \%$ & $3 \%$ & $-34 \%$ & $31 \%$ \\
\hline & Peak (m³/s) & 0.08 & 0.09 & 0.59 & 0.86 & 0.15 & 0.47 & 0.1 & 0.16 & 0.1 & 0.16 \\
\hline & $\%$ Error & $12 \%$ & $-11 \%$ & $1 \%$ & $19 \%$ & $14 \%$ & $-6 \%$ & $-13 \%$ & $21 \%$ & $-16 \%$ & $22 \%$ \\
\hline & NSE & 0.85 & 0.75 & 0.93 & 0.88 & 0.67 & 0.92 & 0.57 & 0.34 & -0.93 & -0.18 \\
\hline & Time to Peak (min) & 180 & 40 & 20 & 15 & 35 & 25 & 25 & 25 & 60 & 35 \\
\hline
\end{tabular}

Table 4 Results of the 2016-04 to 2016-05 simulation for section 81.

\begin{tabular}{|c|c|c|c|c|c|c|c|c|c|c|c|}
\hline \multirow[t]{4}{*}{ Rain Events } & Event & 1 & 2 & 3 & 4 & 5 & 6 & 7 & 8 & 9 & 10 \\
\hline & Date & 19-Apr & 23-Apr & 26-Apr & 1-May & 3-May & 4-May & 5-May & 6-May & 8-May & 13-May \\
\hline & Rainfall (mm) & 0.51 & 2.29 & 6.86 & 12.7 & 2.54 & 12.45 & 3.81 & 2.29 & 0.51 & 2.54 \\
\hline & Duration (h) & 6 & 17 & 8 & 27 & 13 & 11 & 13 & 9 & 6 & 10 \\
\hline \multirow[t]{3}{*}{ Observed } & Total Discharge $\left(\mathrm{m}^{3}\right)$ & 294 & 1006 & 1192 & 2491 & 733 & 2031 & 764 & 510 & 358 & 469 \\
\hline & Peak (m³/s) & 0.02 & 0.04 & 0.25 & 0.31 & 0.03 & 0.18 & 0.03 & 0.08 & 0.02 & 0.03 \\
\hline & Time to Peak (min) & 70 & 40 & 15 & 25 & 30 & 15 & 10 & 10 & 180 & 25 \\
\hline \multirow[t]{6}{*}{ Empirical Model } & Total Discharge $\left(\mathrm{m}^{3}\right)$ & 260 & 819 & 1302 & 2968 & 1060 & 2140 & 793 & 583 & 398 & 881 \\
\hline & $\%$ Error & $-12 \%$ & $-19 \%$ & $9 \%$ & $19 \%$ & $45 \%$ & $5 \%$ & $4 \%$ & $14 \%$ & $-11 \%$ & $88 \%$ \\
\hline & Peak $\left(\mathrm{m}^{3} / \mathrm{s}\right)$ & 0.01 & 0.02 & 0.21 & 0.30 & 0.04 & 0.19 & 0.03 & 0.05 & 0.03 & 0.05 \\
\hline & $\%$ Error & $-40 \%$ & $-40 \%$ & $-15 \%$ & $-2 \%$ & $28 \%$ & $5 \%$ & $-1 \%$ & $-37 \%$ & $54 \%$ & $54 \%$ \\
\hline & NSE & 0.42 & 0.52 & 0.78 & 0.88 & -0.47 & 0.86 & 0.85 & -0.55 & -21 & -4.6 \\
\hline & Time to Peak (min) & 70 & 30 & 20 & 15 & 15 & 15 & 20 & 20 & 60 & 30 \\
\hline \multirow[t]{6}{*}{ Fractal Model } & Total Discharge $\left(\mathrm{m}^{3}\right)$ & 264 & 921 & 1394 & 3078 & 1083 & 2249 & 806 & 597 & 402 & 909 \\
\hline & $\%$ Error & $-10 \%$ & $-8 \%$ & $17 \%$ & $24 \%$ & $48 \%$ & $11 \%$ & $5 \%$ & $17 \%$ & $12 \%$ & $94 \%$ \\
\hline & Peak $\left(\mathrm{m}^{3} / \mathrm{s}\right)$ & 0.02 & 0.03 & 0.23 & 0.33 & 0.05 & 0.20 & 0.03 & 0.06 & 0.03 & 0.06 \\
\hline & $\%$ Error & $-13 \%$ & $-18 \%$ & $-9 \%$ & $7 \%$ & $37 \%$ & $10 \%$ & $6 \%$ & $-31 \%$ & $68 \%$ & $62 \%$ \\
\hline & NSE & 0.5 & 0.75 & 0.75 & 0.88 & -0.67 & 0.83 & 0.80 & -0.74 & -25 & -5.6 \\
\hline & Time to Peak (min) & 70 & 30 & 20 & 15 & 15 & 15 & 20 & 20 & 60 & 30 \\
\hline
\end{tabular}



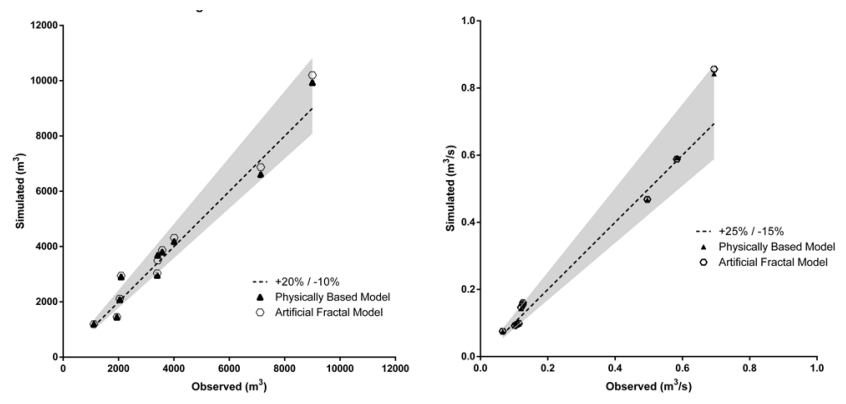

Figure 9 Event summary (total discharge, left, and peak discharge, right) for the simulations in East Boston section 77 .
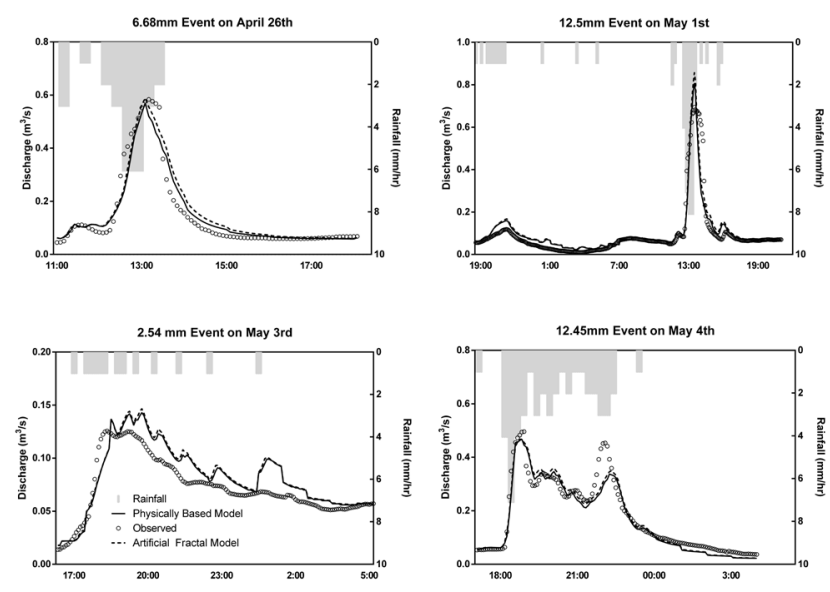

Figure 10 Selected storms for the empirical and fractal simulated networks in East Boston section 77.

The results for section 81 are presented in the same way as for section 77. The summary of events for section 81 is shown in Table 4 above. These results are graphically represented in Figure 11. Select hydrographs are shown in Figure 12.
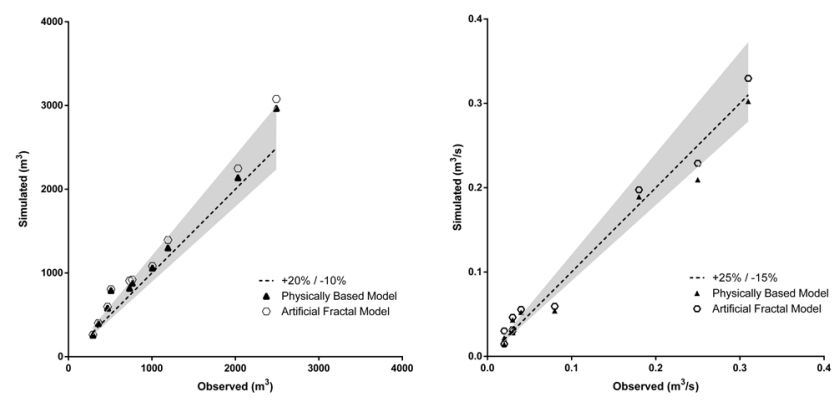

Figure 11 Event summary (total discharge, left, and peak discharge, right) for the simulations in East Boston section 81 .
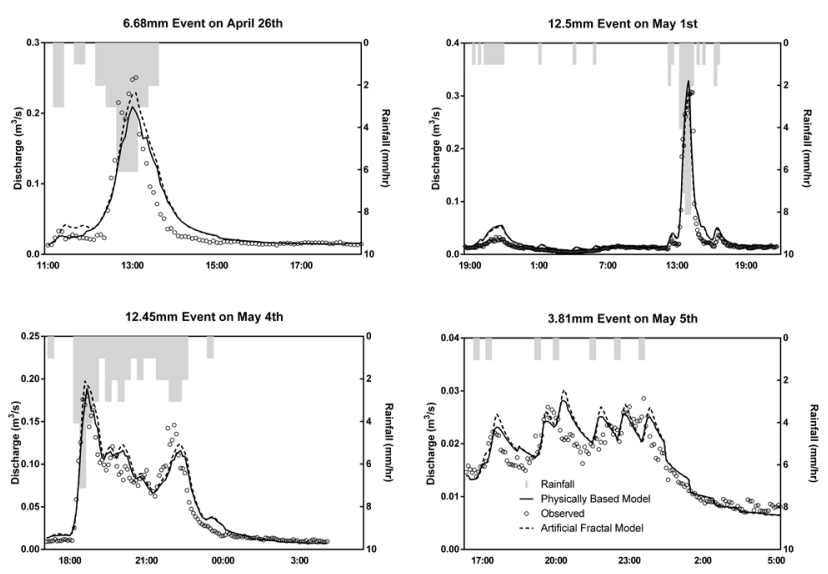

Figure 12 Selected storms for the empirical and fractal simulated network in East Boston section 81.

\section{Discussion}

\subsection{Assessing Model Quality}

In both the empirical and fractal models in section 77, smaller events were modeled less accurately than larger events. For both the empirical model and the fractal model NSE was $0.88-0.93$ for storms $>5 \mathrm{~mm}$, and some smaller events $<5 \mathrm{~mm}$ had no correlation. NSE values $>0.75$ are considered very good and values $>0.5$ are considered satisfactory (Moriasi et al. 2007). The largest storm in the simulation period was $12.7 \mathrm{~mm}$ on 2016-05-01. In this event, both models overpredicted total flow and, most noticeably, peak flow. This could be due to the models underrepresenting the storage capacity of the catchment, or perhaps, because the peak occurs relatively quickly, the sewer flow monitoring device at a 5 min sampling interval did not sample the highest peak flow. Despite the differences between predicted and observed flow, when comparing predicted total discharge volume and peak discharge rate to the observed results throughout the study period, both models meet the Wastewater Planning Users Group (2002) criteria for good model performance with the exception of three smaller events on 2016-05-05 (3.81 mm), 201605-06 (0.51 mm), and 2016-05-08 (2.54 mm).

Sources of error for smaller events could be the result of DWF, the flow monitoring device, or the rain gauge input file. DWF was derived as a function of observed flow patterns, and there is some error associated with applying an average DWF pattern through the simulation period that will be most pronounced in the smallest events. This is illustrated in the 2016-05-05 event which shows the effect on the sinusoidal DWF pattern applied to the simulated models. In comparison, the observed flow is steadier than the model predicts. It may also be that because all three occur at the end of the sampling period, the sensor could have gone off calibration. Due to the spatial variability of rainfall events, the rainfall detected by the gauge $1.5 \mathrm{~km}$ away could differ from the rainfall falling directly on the catchment. For the 
larger storms ( $>5 \mathrm{~mm}$ ), the observed time to peak (lag time) was greater by $5 \mathrm{~min}-15 \mathrm{~min}$. This could be because the rain gauge was located in the direction of the prevailing winds. For smaller events, time to peak varied greatly and could be the result of the $15 \mathrm{~min}$ sampling rate and a sensitivity value of $0.254 \mathrm{~mm}$.

The model comparison in section 81 had similar results to the calibrated model in section 77 (empirical model NSE in the range $0.78-0.88$ and fractal model NSE $0.75-0.88$ for storms $>5 \mathrm{~mm}$, with some smaller events $<5 \mathrm{~mm}$ having no correlation). Both the models tended to overpredict total discharge volumes with the fractal model predicting slightly more than the empirical model. The modeled peak flows varied compared to observed peak flows, but for all events the fractal model predicted greater values than the physical model.

While the results of this uncalibrated simulation were expectedly less accurate than for the calibrated model, both models produced comparable simulations for the observed period. When viewing the time series as a whole, both models had strong correlations to observed flows with NSE of 0.85 (empirical) and 0.86 (fractal) in section 77 and NSE of 0.85 (empirical) and 0.75 (fractal) in section 81.

One source of the differences between the two models could be that the conceptual network has less drainage density and a shorter flow path than the empirical network, resulting in a more rapid hydrologic response. As noted in the sensitivity analysis, both surface and conduit roughness had a greater effect in the conceptual model.

\subsection{Analysis of Network Resolution and the Effect of Strahler Ordering}

As previously discussed, a main motivation for employing conceptual networks is to simplify the modeling process. As noted by Cantone and Schmidt (2009), aggressive aggregation of subcatchments in low resolution models can produce inaccurate simulations relative to observed flows (as the result of shorter pipe lengths and longer periods of overland flow where infiltration can occur) which can be avoided by preserving resolution. They also stress the need to incorporate resolution in municipal stormwater modeling which often uses low resolutions models. Artificial networks can provide this level of resolution more readily than their empirical counterparts.

To explore this possibility, ANGel was used to generate artificial models for section 77 based on Strahler orders of 1, 2 and 3 in addition to the 4th. These models featured 1, 10, 24 and 173 subcatchments respectively. The models were each calibrated to observed flow and compared for NSE, total volume and peak flow. These networks are shown in Figure 13. Their empirical parameters are shown in Table 5 and their calibrated parameters in Table 6.

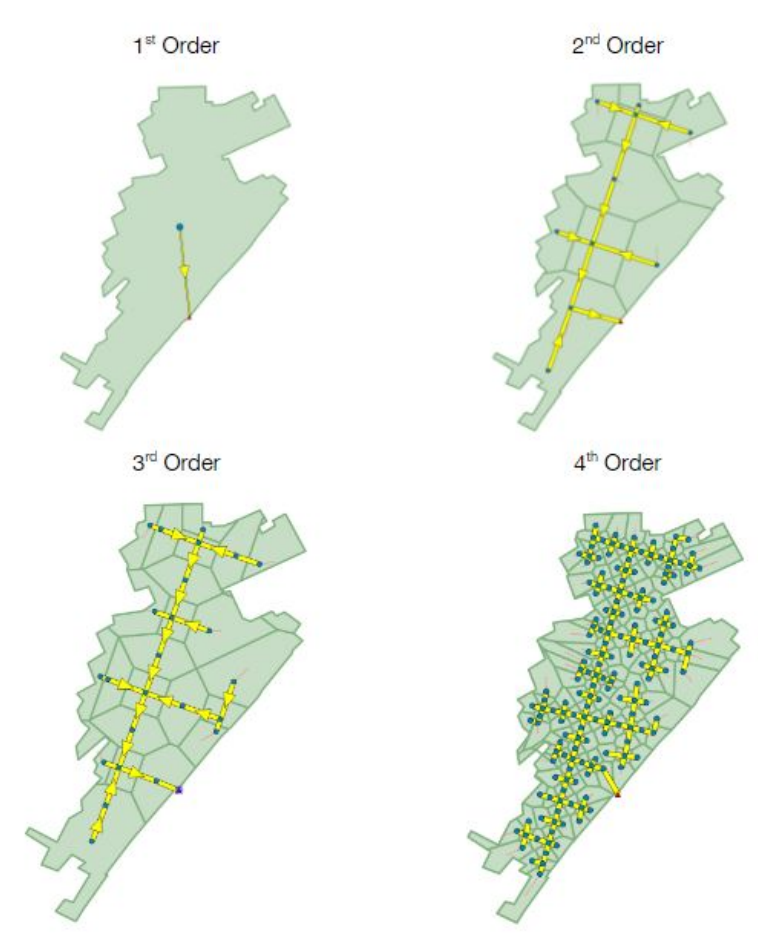

Figure 13 Different resolutions of the fractal network defined by Strahler order representing 1, 10, 24 and 173 subcatchments.

Table 5 Comparison of different Strahler order model network characteristics.

\begin{tabular}{lcccc}
\hline \multicolumn{5}{c}{ Network Summary } \\
\multicolumn{1}{c}{ Section 77 } & Total Pipe Length (m) & \# of Junctions & \# of Subcatchments & Total Area (ha) \\
\hline Empirical & 10502 & 183 & 128 & 54 \\
Artificial 4th Order & 6889 & 173 & 173 & 54 \\
3rd Order & 2647 & 24 & 24 & 54 \\
2nd Order & 2231 & 10 & 10 & 54 \\
1st Order & 381 & 1 & 1 & 54 \\
\hline
\end{tabular}

Table 6 Calibrated sensitive parameters in each Strahler order model for section 77 .

\begin{tabular}{lccccc}
\hline \multicolumn{5}{c}{ Calibrated Parameters } \\
Strahler Order & Slope (\%) & \% Impervious & $n$ Impervious & Catchment Length & Pipe $n$ \\
\hline One & 9.5 & 73 & 0.01 & $1237 \mathrm{~m}$ & 0.003 \\
Two & 8.6 & 71.4 & 0.02 & $266 \mathrm{~m}$ & 0.004 \\
Three & 4.6 & 73.5 & 0.016 & $317 \mathrm{~m}$ & 0.006 \\
Four & 3.7 & 70.9 & 0.047 & $251 \mathrm{~m}$ & 0.005 \\
Empirical & 3 & 69.5 & 0.39 & $244 \mathrm{~m}$ & 0.003 \\
\hline
\end{tabular}

Results are shown in Table 7. A selected hydrograph is shown in Figure 14. Considering the effect of scale, all of the orders show strong correlation with observed flow, with NSE $>0.91$ for the 2016-04-26 $6.68 \mathrm{~mm}$ event. The calibrated model parameters in the 4th order model were closest to the empirical model (which is itself a 4th order network). The main difference between 
the orders were the total pipe length, length of overland flow and slope. Because the smaller order networks have less pipe, more overland flow length is required for the time of the hydrologic response to be consistent with observed flow. In addition, because overland flow is a more influential factor, increasing slope can cause more flashiness in the hydrologic response. In all scenarios, the falling limb of the hydrograph overestimated the observed results. This could be because surface roughness was overestimated or, as previously discussed, the input rain gauge was $1.5 \mathrm{~km}$ away which would shift the time series and make it earlier.

Table 7 Comparison of different Strahler order models.

\begin{tabular}{lcccccc}
\hline & One & Two & Three & Four & Observed & Empirical Model \\
\hline April 26th NSE & 0.94 & 0.91 & 0.95 & 0.93 & - & 0.93 \\
April 26th Total $\left(\mathrm{m}^{3}\right)$ & 4326 & 4366 & 3792 & 4202 & 4010 & 4185 \\
April 26th Peak $\left(\mathrm{m}^{3} / \mathrm{s}\right)$ & 0.60 & 0.61 & 0.52 & 0.57 & 0.58 & 0.59 \\
\hline
\end{tabular}

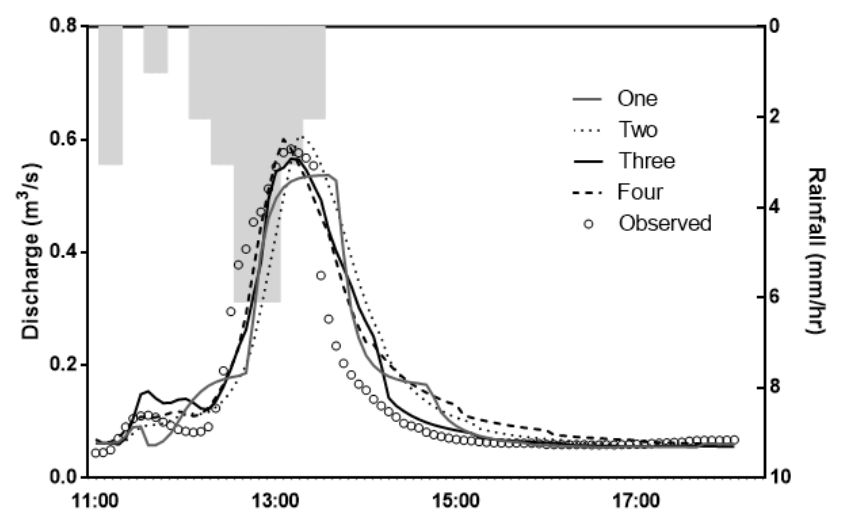

Figure 14 Hydrograph of the $6.68 \mathrm{~mm}$ storm (2016-04-26) illustrating resolution in the fractal model for different Strahler orders.

\subsection{Further Model Development}

One of the main critiques of the fractal models used in this study is that they do not incorporate topological characteristics of the catchment to define conduit and catchment slopes and widths. Digital elevation models (DEMs) have promise in urban hydrologic modeling as they are able to take topographic information and create drainage networks based on elevation gradient (Schellekens et al. 2014). However, because urban drainage networks often do not follow the elevation gradient, as would be expected in natural river basins, generating a model based on a DEM can produce misleading results and so requires information regarding the structure of the network. In one study of applied fractal river basin analysis (Rodriguez et al. 2005), a DEM was used with sewer pipe location data to create a model that gave accurate results for a large urban catchment in France (Rossel et al. 2014). Similarly, Blumensaat et al. (2012) developed a method to use DEM to create conceptual sewer pipe layouts that were similar to actual layouts with pipe diameters based on catchment characteristics giving SWMM simulation results comparable to observed flow (NSE in the range $0.51-0.73$ ). It is possible that using a DEM with a fractal artificial sewer network generating tool such as ANGel will produce more realistic catchment parameters and conduit slopes and thus generate more accurate results, particularly in relation to peak flows.

\section{Conclusions}

This study describes an application of an artificial fractal sewer network model in a highly urban residential catchment. When calibrated, the model produced results that were as accurate as an empirical model. When uncalibrated, the artificial model was able to produce similar results to the empirical model. While this shows that artificial models do not eliminate the need for calibration, for some purposes general estimates are enough. Due to the rapid development of artificial sewer networks, they can be used more readily to obtain these results.

While it is unclear how usable fractal models are in less urbanized areas or places with less homogenous topography, their implementation can add resolution to existing models and avoid issues related to model aggregation. Because many sewer modelers rely on aggregated low resolution models (with catchments often much larger than the 54 ha in this study), this method provides a relatively simple method to potentially improve model accuracy within a reasonable timeframe. Cantone and Schmidt (2009) and Ghosh and Hellweger (2012) showed a much greater difference in their lowest lumped resolution models. This could be because their catchment sizes were much bigger and had more pervious area. Cantone and Schmidt (2009) had a 341 ha catchment and modeled the subcatchments at $50 \%$ impervious in general and $80 \%$ impervious if the subcatchments were primarily roads. Ghosh and Hellweger (2012) modeled the 466 ha of the Faneuil Brook subbasin (a tributary of the lower Charles River) and although no level of imperviousness is listed, the area is less developed than the 54 ha of East Boston used in this study. Based on this analysis, future development of artificial networks should give particular attention to the size of the modeled catchment and the level of imperviousness. If the catchment is $>54$ ha or there is imperviousness $<73 \%$ other factors discussed in the literature can come into play.

Developing this methodology for urban catchments enables many practical applications of sewer management and urban planning. One example relates to the large scale implementation of green stormwater infrastructure (GSI) to mitigate issues relating to flooding, combined sewer overflows and climate change. Alterations to an urban catchment using SWMM LID controls can be modeled relatively quickly using theoretical sewer models and quantitative assessments can quickly be made. Creating high resolution models enables a spatial analysis of the effect of GSI placement throughout the network that is not possible in lower resolution aggregated models. Future work with this method will focus on GSI implementation as a demonstration of the practical applications in engineering and research. 


\section{Data Availability}

Sewer maps and sewer flow data were obtained from the Boston Water Sewer Commission under the GIS Data Exchange Policy. This data is protected by the Boston Water Sewer Commission, but is available by written request to the agency. The GIS tiles requested in this study were as follows: $25 \mathrm{~L}-29 \mathrm{~L}, 25 \mathrm{M}-29 \mathrm{M}$, $23 \mathrm{~N}-31 \mathrm{~N}, 22 \mathrm{O}-310,23 \mathrm{P}-31 \mathrm{P}$ and 24Q-30Q. Standard pricing is $\$ 20 /$ tile. The GIS sewer maps were incorporated into a USEPA SWMM sewer model using PCSWMM version 7.0.2325, which is proprietary software. However the model is viewable with open source USEPA SWMM software version 5 . Access to this model is available upon request (in a reduced form, to preserve data confidentiality) at http://swre.cae.drexel.edu/tools/. The ArcGIS VBA plugin ANGel used in generating artificial models is also available from this link.

\section{Acknowledgments}

Support for this research was provided by the National Science Foundation, CBET 1150994 (CAREER: Integrated Assessments of the Impacts of Decentralized Land Use and Water Management), The National Fish and Wildlife Foundation, 2005-0333-010 (NYSimulation of the Water Quality Impacts of Urban Low Impact Development), and the National Oceanic and Atmospheric Administration, NA15OAR4310147 (Supporting Regional Implementation of Integrated Climate Resilience: Consortium for Climate Risks in the Urban Northeast). The authors also acknowledge the in-kind support provided by Boston Water and Sewer, including access to sewer map GIS databases and sewer flow data.

\section{Conflicts of interest}

None.

\section{References}

Blumensaat, F., M. Wolfram and P. Krebs. 2012."Sewer Model Development Under Minimum Data Requirements." Environmental and Earth Science 65 (5): 1427-37.

Cantone, J. P. and A. R. Schmidt. 2009. "Potential Dangers of Simplifying Combined Sewer Hydrologic/Hydraulic Models." Journal of Hydrologic Engineering 14 (6): 596-605.

Cantone, J. and A. Schmidt. 2011. “Improved Understanding and Prediction of the Hydrologic Response of Highly Urbanized Catchments through Development of the Illinois Urban Hydrologic Model." Water Resources Research 47 (8): W08538.

CHI (Computational Hydraulics International). 2017. PCSWMM (7.0.2330). Guelph: Computational Hydraulics International.

CHI (Computational Hydraulics International). 2018. "Calibrating a SWMM5 Model Using the SRTC Tool." Guelph: Computational Hydraulics International. https://support.chiwater.com/78011/calibrating-a-swmm5model-using-the-srtc-tool
Ghosh, I. and F. L. Hellweger. 2012. "Effects of Spatial Resolution in Urban Hydrologic Simulations." Journal of Hydrologic Engineering 17:129-37.

Ghosh, I., F. L. Hellweger and T. G. Fritch. 2006. "Fractal Generation of Artificial Sewer Networks for Hydrologic Simulations." In Proceedings of the ESRI International User Conference, San Diego, California, August 7-11, 2006. Redlands, CA: ESRI. http://proceedings.esri.com/library/userconf/proc06/papers/papers/pap_1997.pdf

Goldstein, A. 2011. Comparison of a High and Low Spatial Resolution Model for an Urban Block and Implications for Depicting Low Impact Development. Philadelphia, PA: Drexel University. MS thesis.

Hack, J. T. 1957. Studies of Longitudinal Stream Profiles in Virginia and Maryland. Washington, DC: U.S. Department of the Interior Geological Survey. Geological. Survey Professional Paper 294-B.

https://pubs.usgs.gov/pp/0294b/report.pdf

Huber, W. C., L. Cannon and M. Stouder. 2006. BMP Modeling Concepts and Simulation. Cincinnati, OH: U.S. Environmental Protection Agency Office of Research and Development National Risk Management Laboratory. EPA/600/R-06/033. https://www.epa.gov/sites/production/files/2015-10/documents/bmp_tools_complex.pdf

Jeffers, S. 2017. Using Fractal Geometries to Understand Urban Drainage Networks and Green Stormwater Infrastructure Development. Philadelphia, PA: Drexel University. PhD dissertation.

https://idea.library.drexel.edu/islandora/object/ idea\%3A7555

Mandelbrot, B. 1967. "How Long is the Coast of Britain? Statistical Self-Similarity and Fractional Dimension." Science 156 (3775): 636-8.

Möderl, M., D. Butler and W. Rauch. 2009. "A Stochastic Approach for Automatic Generation of Urban Drainage Systems." Water Science and Technology 59 (6): 1137-43.

Moriasi, D. N., J. G. Arnold, M. W. Van Liew, R. L. Bingner, R. D. Harmel and T. L. Veith. 2007. "Model Evaluation Guidelines for Systematic Quantification of Accuracy in Watershed Simulations." American Society of Agricultural and Biological Engineers 50 (3): 885-900.

NCRS (National Resource Conservation Service). 2017. “Web Soil Survey."

Rodriguez, F., C. Cudennec and H. Andrieu. 2005. “Application of Morphological Approaches to Determine Unit Hydrographs of Urban Catchments." Hydrological Processes 19 (5): 1021-35.

Rodríguez-Iturbe, I. and A. Rinaldo. 2001. Fractal River Basins, 1. Cambridge: Cambridge University Press.

Rossel, F., J. Gironás, A. Mejía, A. Rinaldo and F. Rodriguez. 2014. "Spatial Characterization of Catchment Dispersion 
Mechanisms in an Urban Context." Advances in Water Resources 74:290-301.

Rossman, L. 2017. Storm Water Management Model Reference Manual Volume II-Hydraulics. Cincinnati, OH: U.S. Environmental Protection Agency Office of Research and Development National Risk Management Laboratory.

Ryan, B. 2007. “Fractaldimensionexample.PNG." Wikimedia Commons.

https://commons.wikimedia.org/wiki/File:Fractaldimensionexample.PNG

Schellekens, J., R. J. Brolsma, R. J. Dahm, G. V. Donchyts and H. C. Winsemius. 2014. "Rapid Setup of Hydrological and Hydraulic Models using OpenStreetMap and the SRTM Derived Digital Elevation Model." Environmental Modelling \& Software 61:98-105.

Tory R. Walker Engineering. 2016. Improving Accuracy in Continuous Simulation Modeling: Guidance for Selecting Pervious Overland Flow Manning's n Values in the San Diego Region. http://www.projectcleanwater.org/images/stries/Docs/ LDW/BMPDM/TRWE_SD_Manning_Roughness0816.pdf?1361c1\&1361c1

Turcotte, D. L. and W. I. Newman. 1996. "Symmetries in Geology and Geophysics." PNAS, Proceedings of the National Academy of Science 93 (25): 14295-300.
U.S. Census Bureau. 2010. Decennial Census of Population and Housing-2010 Census. Washington, DC: U.S. Census Bureau.

https://www.census.gov/programs-surveys/decennial-census/decade.2010.html

USEPA (U.S. Environmental Protection Agency). 2017. Storm water management model (SWMM). Durham, NC: U.S. EPA Research, Office of Science Information Management. https://www.epa.gov/water-research/storm-watermanagement-model-swmm

USEPA (U.S. Environmental Protection Agency). 2018. National Stormwater Calculator. Durham, NC: U.S. EPA Research, Office of Science Information Management. https://www.epa.gov/water-research/national-stormwater-calculator

Veneziano, D. and A. Langousis. 2010. "Scaling and Fractals in Hydrology." In Advances in Data-based Approaches for Hydrologic Modeling and Forecasting, edited by B. Sivakumar and R. Berndtsson. Singapore: World Scientific Publishing.

WaPUG (Wastewater Planning Users Group). 2002. Guide to the Quality Modeling of Sewer Systems. Marlow, Bucks: Wastewater Planning Users Group. 